\title{
Variola virus F1L is a Bcl-2-like protein that unlike its vaccinia virus counterpart inhibits apoptosis independent of Bim
}

\author{
B Marshall ${ }^{1,2}$, H Puthalakath ${ }^{1,2}$, S Caria ${ }^{1,2}$, S Chugh ${ }^{1,2,5}$, M Doerflinger $^{1,2}$, PM Colman $^{3,4}$ and M Kvansakul ${ }^{, 1,2,3}$
}

Subversion of host cell apoptosis is an important survival strategy for viruses to ensure their own proliferation and survival. Certain viruses express proteins homologous in sequence, structure and function to mammalian pro-survival B-cell lymphoma 2 (Bcl-2) proteins, which prevent rapid clearance of infected host cells. In vaccinia virus (VV), the virulence factor F1L was shown to be a potent inhibitor of apoptosis that functions primarily be engaging pro-apoptotic Bim. Variola virus (VAR), the causative agent of smallpox, harbors a homolog of F1L of unknown function. We show that VAR F1L is a potent inhibitor of apoptosis, and unlike all other characterized anti-apoptotic Bcl-2 family members lacks affinity for the Bim Bcl-2 homology $3(\mathrm{BH} 3)$ domain. Instead, VAR F1L engages Bid BH3 as well as Bak and Bax BH3 domains. Unlike its VV homolog, variola F1L only protects against Bax-mediated apoptosis in cellular assays. Crystal structures of variola F1L bound to Bid and Bak BH3 domains reveal that variola F1L forms a domain-swapped Bcl-2 fold, which accommodates Bid and Bak BH3 in the canonical Bcl-2-binding groove, in a manner similar to VV F1L. Despite the observed conservation of structure and sequence, variola F1L inhibits apoptosis using a startlingly different mechanism compared with its VV counterpart. Our results suggest that unlike during VV infection, Bim neutralization may not be required during VAR infection. As molecular determinants for the human-specific tropism of VAR remain essentially unknown, identification of a different mechanism of action and utilization of host factors used by a VAR virulence factor compared with its VV homolog suggest that studying VAR directly may be essential to understand its unique tropism.

Cell Death and Disease (2015) 6, e1680; doi:10.1038/cddis.2015.52; published online 12 March 2015

Variola virus (VAR), the causative agent of smallpox, is a member of the poxvirus family and belongs to the orthopoxviridae. Despite its successful eradication nearly 30 years ago, VAR remains an ongoing concern because of its potential use as a bioterrorism agent. ${ }^{1}$ The threat of intentional use of VAR coupled with the absence of an FDA-approved drug for the prevention or treatment of smallpox infection is cause for considerable interest in the development of small-molecule therapeutics against VAR. Current strategies for dealing with smallpox are based on vaccination using live vaccinia virus $(\mathrm{VV}){ }^{2,3}$ a closely related member of the orthopoxvirus genus, which shares $>90 \%$ sequence identity with VAR. Vaccination using live VV, however, can cause serious complications, ${ }^{4}$ underscoring the need for effective anti-viral treatments, particularly since anti-viral treatment may be a more efficacious strategy compared with vaccination. ${ }^{5}$ Recent strategies to target VAR for small-molecule therapeutics included the use of polymerase inhibitors, ${ }^{6}$ notably Cidofovir, inhibitors of extracellular virus formation ${ }^{7}$ and tyrosine kinase inhibitors including Gleevec. ${ }^{8,9}$ Cidofovir is currently the only approved antiviral drug for the treatment of orthopoxviruses, although it is not approved for smallpox treatment. Other host-virus interactions have been identified that may be suitable drug targets ${ }^{10,11}$ but currently require further investigation.

Several poxvirus members other than VAR have been shown to rely on virulence factors that prevent premature host cell demise via programmed cell death or apoptosis, ${ }^{12-16}$ thus ensuring survival and proliferation. The B-cell lymphoma 2 (Bcl-2) protein family is a key mediator for maintaining cell survival or to drive apoptosis, thereby removing infected, damaged or unwanted cells, ${ }^{17}$ and sequence, structural and functional orthologs of $\mathrm{Bcl}-2$ have been found in a number of poxviruses. ${ }^{18}$ Certain viral Bcl-2-like proteins were only identified as family members after their 3D structures were determined, owing to their complete lack of sequence identity to mammalian $\mathrm{Bcl}-2$ proteins. This group of proteins include the myxoma virus $\mathrm{M}_{11 \mathrm{~L}^{12}}$ and VV F1L ${ }^{15}$ and N1L. ${ }^{19}$ Myxoma virus $\mathrm{M} 11 \mathrm{~L}$ was shown to adopt the classical $\mathrm{Bcl}-2$ fold ${ }^{20,21}$ that utilizes the canonical Bcl-2 homology 3 (BH3)-binding groove to engage $\mathrm{BH} 3$ ligands to exert its pro-survival effect. VV F1L also adopts a Bcl-2 fold, but unlike M11L it exists as a domain-swapped dimer, ${ }^{22,23}$ whereas $\mathrm{N} 1 \mathrm{~L}$ also adopted a dimeric $\mathrm{Bcl}-2$ fold but with a different dimeric arrangement. ${ }^{24,25}$

Although F1L from VAR has not previously been investigated, the VV homolog is well characterized. VV F1L has been

\footnotetext{
${ }^{1}$ Department of Biochemistry, La Trobe University, Kingsbury Drive, Melbourne, 3086 Victoria, Australia; ${ }^{2}$ La Trobe Institute for Molecular Science, La Trobe University, Kingsbury Drive, Melbourne, 3086 Victoria, Australia; ${ }^{3}$ Walter and Eliza Hall Institute of Medical Research, 1G Royal Parade, Parkville, 3052 Victoria, Australia and ${ }^{4}$ Department of Medical Biology, University of Melbourne, Parkville, Victoria 3010, Australia

*Corresponding author: M Kvansakul, Department of Biochemistry, La Trobe University, Kingsbury Drive, Bundoora, 3086 Victoria, Australia. Tel: +61 394792263 ; Fax: +61 39479 2467. E-mail: m.kvansakul@latrobe.edu.au

${ }^{5}$ Current address: CSL Limited, Bio21 Institute, 30 Flemington Road, Parkville, Victoria 3052, Australia

Abbreviations: Bcl-2, B-cell lymphoma 2; VAR, variola virus; VV, vaccinia virus; $\mathrm{BH}, \mathrm{Bcl}-2$ homology; MEF, mouse embryonic fibroblast

Received 26.7.14; revised 26.1.15; accepted 27.1.15; Edited by R Johnston
} 
shown to inhibit the mitochondrial pathway of apoptosis by replacing $\mathrm{Mcl}-1^{26}$ and interacts with the isolated $\mathrm{BH} 3$ domains of Bim, Bax and Bak, ${ }^{23}$ which are bound in the canonical $\mathrm{Bcl}-2$ binding groove. ${ }^{22}$ Furthermore, an F1L-deficient VV potently causes Bak/Bax-mediated apoptosis. ${ }^{15,27}$ Functionally, VV $\mathrm{F} 1 \mathrm{~L}$ appears to rely primarily on neutralization of Bim in the context of a viral infection. ${ }^{22}$ Given the close similarity between VAR and VV, VAR may also rely on inhibition of host cell apoptosis for successful infection and proliferation. Disruption of VAR ability to inhibit apoptosis thus may constitute an attractive strategy for small-molecule-based intervention. To investigate this possibility, we performed a biochemical, structural and functional characterization of VAR F1L. Here we report that despite possessing a nearly identical 3D structure and sequence, VAR F1L inhibits apoptosis via a different mechanism compared with its homolog in VV.

\section{Results}

Given the high sequence identity of VAR F1L with VV F1L (Figure 1a) and the location of primary sequence variations (all of which are away from the identified BH3-domain-binding groove in VV F1L (Figure 1b and Supplementary Figure 1)), we surmised that VAR F1L would display a ligand-binding behavior similar to VV F1L. Using recombinant VAR F1L we tested a panel of pro-apoptotic $\mathrm{BH}$-domain ligands using isothermal calorimetry (Figure 1c). Previously, we showed that VV F1L exhibited a highly selective BH3-domain ligandbinding profile, with high affinity for pro-apoptotic Bim $\left(K_{\mathrm{D}}=200 \mathrm{nM}\right)$, and considerably lower affinity for Bax and Bak BH3 domains ( $K_{\mathrm{D}}$ of 2000 and $4300 \mathrm{nM}$, respectively). ${ }^{23}$ Similarly, VAR F1L bound Bax and Bak BH3 domains weakly with $K_{\mathrm{D}}$ values of 920 and $2640 \mathrm{nM}$, respectively. Unexpectedly, VAR F1L showed no detectable affinity for Bim BH3, and only weakly bound Bid from the BH3-only proteins with a $K_{\mathrm{D}}$ of $3220 \mathrm{nM}$. Considering the weak affinity of VAR F1L for Bax and Bak $\mathrm{BH} 3$ ligands, we then investigated if VAR F1L is able to engage and restrain full-length Bax and Bak. For this purpose, we utilized a yeast-based assay in which we expressed full-length Bak, Bax and VAR F1L. The assay is based on the observation that Bax or Bak overexpression is lethal in yeast, but can be repressed by co-expression of $\mathrm{Bcl}-2$, $\mathrm{Bcl}-\mathrm{x}_{\mathrm{L}}, \mathrm{Mcl}-1$ or $\mathrm{A} 1$. Similar to endogenous mammalian

a

VAR F1L MYNSMLPMFMCNNIVDDIDDIDDIDDIDDIDDIDDIDDKASNNDDHNYVYPLPENMVYRF 60 VV F1L ----MLSMFMCNNIVDYVDGI-----------VQDIEDEASNNVDHDYVYPLPENMVYRF 45 $\begin{array}{ccc}\alpha 0 & \alpha 1 & \alpha 2 \\ \text { HHHHHHHH } & \text { HHHHHHHHHHHHHHHHHHHHHHHH } & \text { HHHHHHHHHHHHHHHHHHH } \\ \text { STHNILDYLSTERDHVMMAVOYYMSKORLDDLYROLPTKTRSYIDIINMYCDKVNNDYN } & 120\end{array}$ $\begin{array}{ccc}\alpha 0 & \alpha 1 & \alpha 2 \\ \text { HHHHHHHH } & \text { HHHHHHHHHHHHHHHHHHHHHH } & \text { HHHHHHHHHHHHHHHHH } \\ \text { STNILDYLSTERDHVMMAVOYYMSKORLDDLYROLPTKTRSYIDIINMYCDKVNNDYN } & 120\end{array}$

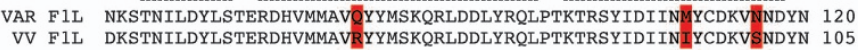
$\alpha 3$ $\alpha 3$ $\alpha 4$

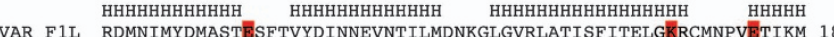
VV F1L RDMNIMYDMASTKSFTVYDINNEVNTILMDNKGLGVRLATISFITELGRRCMNPVKTIKM 165 $\alpha 6$
HнHНHНHн $\alpha 7$

VAR F1L FTLLSHTICDDCFIDYITDISPPDNTIPNISTREYLKLIGITAIMFATYKTLKYMIG 237 VV F1L FTLLSHTICDDCF VDYITDISPPDNTIPNTSTREYLKLIGITAIMFATYKTLKYMIG 222 pro-survival Bcl-2, VAR F1L is able to prevent both Bak- and Bax-induced yeast death (Supplementary Figure 2), indicating that VAR F1L is able to directly engage both Bak and Bax. In contrast, VV F1L has only been shown to bind Bak but not Bax in yeast (Supplementary Figure 2), as previously observed in mammalian cells. ${ }^{28}$

Structural basis for VAR F1L BH3 domain ligand binding. To investigate the molecular basis for Bid, Bak and Bax $\mathrm{BH} 3$ domain binding by VAR F1L, we determined crystal structures of VAR F1L in complex with Bak and Bid BH3 domain peptides (Figures $2 \mathrm{a}$ and $\mathrm{d}$, Table 1). As observed previously for VV F1L, ${ }^{22,23}$ VAR F1L adopts a Bcl-2-like fold that forms a domain-swapped Bcl-2 with similar binding

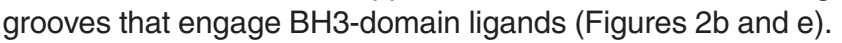
Superimposition of bound Bak and Bid BH3 backbones indicate that both ligands are bound in near identical manner (Supplementary Figures $3 a$ and b). In the VAR F1L:Bak BH3 complex (Figure 2c), residues V75, L78, I81, I85 protrude into four pockets in the VAR F1L-binding groove, similar to the equivalent hydrophobic residues in Bid (Figure 2f; I86, L90, v93, M97).

Comparison of VAR_F1L:Bak BH3 with VV_F1L:Bak BH3 complex. Superimposition of VV F1L with VAR F1L from their respective complexes with $\mathrm{Bak} \mathrm{BH} 3$ yields a root-meansquare deviation of $0.9 \AA$ over $138 \mathrm{C} a$ atoms, with the only notable differences in side chain orientations between VV F1L and VAR F1L occurring at F135 (Supplementary Figure 4). Overall, the VV F1L and VAR_F1L complexes with Bak appear to be near identical.

VAR F1L only inhibits Bax but not Bak-mediated apoptosis. To identify differences in anti-apoptotic activity between VAR and VV F1L, we retrovirally transfected VAR F1L into wild-type, $\mathrm{Bax}^{-1-}, \mathrm{Bak}^{-1-}$ and $\mathrm{Bax}^{-/-} / \mathrm{Bak}^{-1-} \mathrm{DKO}$ cells and treated them with thapsigargin to induced apoptosis via ER stress. Unexpectedly, VAR F1L was unable to protect both wildtype and $\mathrm{Bax}^{-1-}$ mouse embryonic fibroblasts (MEFs), whereas $\mathrm{Bak}^{-1-}$ MEFs were efficiently protected from apoptosis (Figure $3 a$ ) in a manner similar to $\mathrm{Bcl}-2$ (Figure $3 b$ ), suggesting that VAR F1L exclusively inhibits Bax-mediated apoptosis. Similar results were obtained after serum

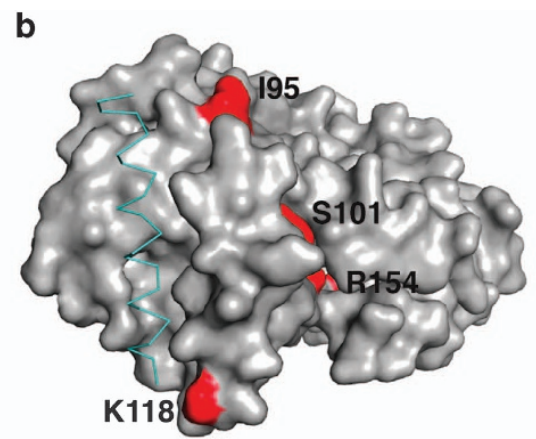

Figure 1 (a) Sequence alignment of vaccinia virus (VV) with variola virus (VAR) F1L. Red denotes sequence differences in the Bcl-2 domain, H indicates helices. (b) Sequence variations between VV and VAR F1L are mapped in red on a molecular surface of VV F1L (gray). (c) BH3-binding profile of VAR_F1L. $K_{\mathrm{D}}$ values were determined by isothermal calorimetry 
a

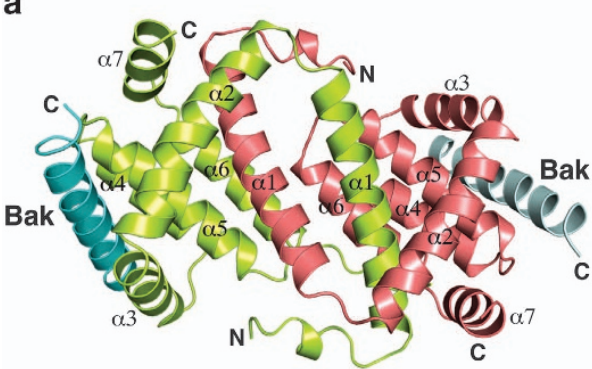

d

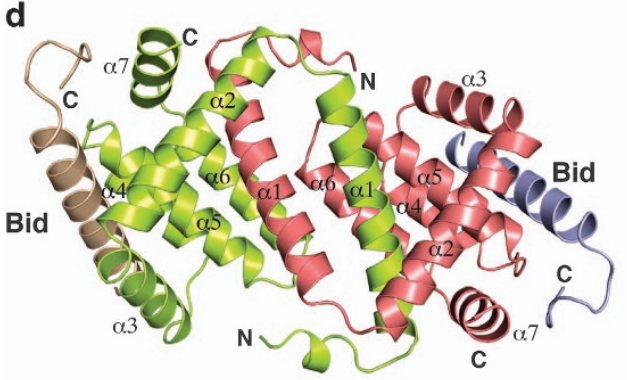

b

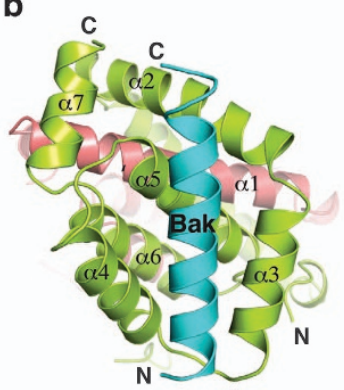

e

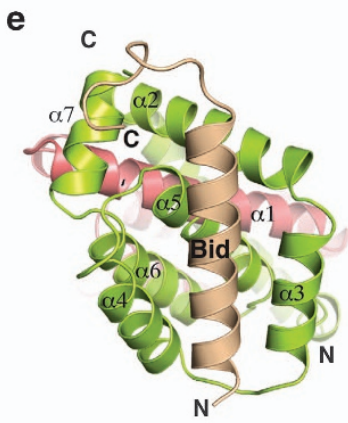

C

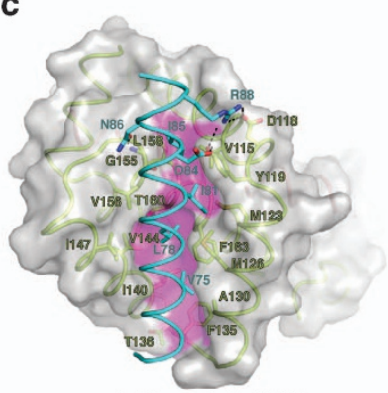

F1L : Bak BH3

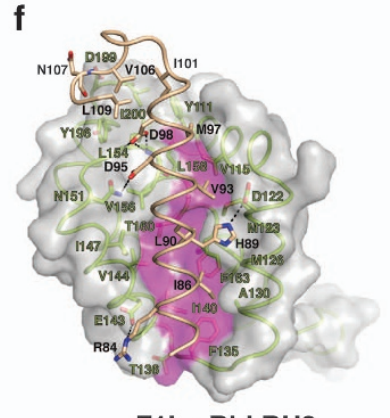

f

Figure 2 Structures of VAR F1L:Bak and Bid BH3 complexes. (a) Cartoon diagram of F1L:Bak BH3 complex. F1L chains are shown as a cartoon (lime and salmon), with helices $\alpha$ 1-7 labeled. Two Bak BH3 chains are show in cyan and light blue. (b) Cartoon diagram of F1L:Bak BH3 complex. This view looks into the hydrophobic BH3-binding grove, which is formed by helices $\alpha 2-5$. F1L helices $\alpha 2-7$ from monomer 1 (lime) are labeled, as is helix $\alpha 1^{\prime}$ from monomer 2 (salmon). Bak BH3 is shown in cyan. (c) Cartoon diagram of $\mathrm{F} 1 \mathrm{~L}: \mathrm{Bid} \mathrm{BH} 3$ complex. F1L (lime and salmon) in complex with Bid BH3 (wheat and lilac). The view is as in a. (d) Cartoon diagram of $\mathrm{F} 1 \mathrm{~L}: \mathrm{Bid} \mathrm{BH} 3 \mathrm{complex}$. This view is as in b. F1L helices $\alpha 2-7$ from monomer 1 (lime) are labeled, as is helix $\alpha 1^{\prime \prime}$ from monomer 2 (salmon). Bid BH3 is shown in wheat. (e) Stereo diagram of the F1L (lime):Bak (cyan) complex interface. The F1L surface is shown in gray, except for magenta shading indicating the floor of the peptide-binding groove. F1L residues are labeled in lime, Bim $\mathrm{BH} 3$ residues are labeled in cyan. (f) Stereo diagram of the F1L (lime):Bim (wheat) complex interface. View and labeling is as in c, except for labeling of Bid residues (in black)

Table 1 Crystallographic statistics

\begin{tabular}{|c|c|c|}
\hline Crystal & F1L: Bak & F1L: Bid \\
\hline \multicolumn{3}{|l|}{ Data collection and phasing } \\
\hline Spacegroup & 12 & F222 \\
\hline Resolution range $(\AA)$ & $40-2.55$ & $50-1.75$ \\
\hline Unique reflections & 45043 & 17113 \\
\hline Multiplicity ${ }^{\mathrm{a}}$ & $4.1(4.1)$ & $13.3(9.2)$ \\
\hline Completeness (\%) ${ }^{\mathrm{a}}$ & $99.9(100.0)$ & $97.1(80.4)$ \\
\hline$R_{\text {merge }} \mathrm{a}^{\mathrm{b}}$ & $0.075(0.656)$ & $0.062(0.459)$ \\
\hline Mn I/ol & $12.0(2.2)$ & $39.0(4.1)$ \\
\hline \multicolumn{3}{|l|}{ Refinement } \\
\hline Resolution range $(\AA)$ & $39.7-2.55$ & $40.5-1.75$ \\
\hline Reflections (working set/test set) & $41807 / 2127$ & $15817 / 842$ \\
\hline Protein atoms & 7943 & 1351 \\
\hline Solvent atoms & $98 \mathrm{H}_{2} \mathrm{O}$ & $91 \mathrm{H}_{2} \mathrm{O}$ \\
\hline$R_{\text {cryst }} / R_{\text {free }}{ }^{\mathrm{c}}$ & $0.197 / 0.242$ & $0.172 / 0.213$ \\
\hline r.m.s.d. bonds $(\AA)$ & 0.002 & 0.012 \\
\hline r.m.s.d. angles $\left({ }^{\circ}\right)$ & 0.5 & 1.2 \\
\hline Ramachandran plot (\%) ${ }^{d}$ & $95.1 / 4.9 / 0.0 / 0.0$ & $98.0 / 2.0 / 0.0 / 0.0$ \\
\hline
\end{tabular}

${ }^{a}$ Numbers in parentheses refer to the highest resolution shells. ${ }^{\mathrm{b}} R_{\text {merge }}=$ $\Sigma_{h} \Sigma_{i}\left|l_{i}(h)-<l(h)>\right| / \Sigma_{n} \Sigma_{i} l_{i}(h)$, where $l_{i}(h)$ is the th measurement of reflection $h$ and $\langle I(h)\rangle$ is the weighted mean of all measurements of $h \cdot{ }^{\mathrm{c}} \mathrm{R}=\Sigma_{h} \mid F_{\mathrm{obs}}-F_{\mathrm{cald}} / /$ $\Sigma_{h} F_{\text {obs }}$, where $F_{\text {obs }}$ and $F_{\text {calc }}$ are the observed and calculated structure factor amplitudes, respectively. $R_{\text {cryst }}$ and $R_{\text {free }}$ were calculated using the working and test set, respectively. ${ }^{\mathrm{d}}$ Residues in most favoured, additionally allowed, generously allowed and disallowed regions

withdrawal, with VAR F1L maintaining viability of $\mathrm{Bak}^{-/-} \mathrm{MEFs}$ but not wild-type and $\mathrm{Bax}^{-1-}$ MEFs (Supplementary Figure 5). Overall, the cellular assays mirror our peptide-binding data obtained by ITC, where the lower affinity ligand Bak is not inhibited in a cellular context. Considering the peptide-binding data, we next investigated whether VAR F1L is able to protect against Bim- and Bid-induced apoptosis. 293T cells were transfected with either Bim $\mathrm{EL}_{\mathrm{L}}$ or Bid. VAR F1L protected against both $\operatorname{Bim}_{\mathrm{EL}}(P=0.006)$ or Bid-mediated apoptosis $(P=0.0027)$, with comparable levels of protection observed with $\mathrm{Bcl}-2$.

\section{Discussion}

Interactions between pro- and anti-apoptotic Bcl-2 family members are critical for the regulation of apoptosis during normal development as well as during disease states including viral infections or cancer. ${ }^{17}$ Compelling evidence points to a critical role for viral $\mathrm{Bcl}-2$ proteins during the viral life cycle, particularly viral infectivity and proliferation. ${ }^{12,15,29}$ No antiapoptotic activity for VAR encoded proteins has been demonstrated to date, although a number of proteins from the closely related VV have been reported to manipulate host cell death signaling. ${ }^{15,30}$ We have now shown biochemically that VAR F1L is able to engage a limited number of proapoptotic Bcl-2 proteins including Bid, Bak and Bax. This binding profile is highly unusual, as all reported cellular or viral anti-apoptotic $\mathrm{Bcl}-2$ family members engage $\mathrm{Bim},{ }^{31}$ the sole pan pro-survival antagonist of the $\mathrm{Bcl}-2$ family, ${ }^{32}$ making VAR F1L the first reported exception. This observation was unexpected as VV $\mathrm{F} 1 \mathrm{~L}$ binds $\mathrm{Bim} \mathrm{BH} 3$ in vitro and in vivo. ${ }^{22,28}$ Furthermore, VV F1L prevents both Bak- and Bax-mediated apoptosis in cell-based assays, ${ }^{26,28}$ whereas 

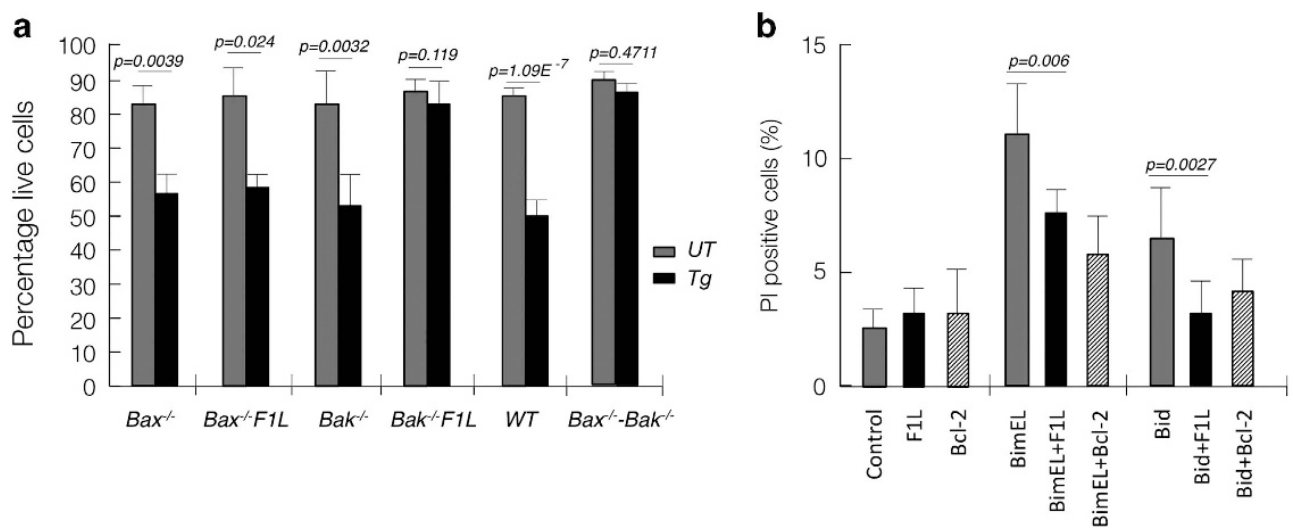

Figure 3 VAR F1L inhibits Bax- but not Bak-mediated apoptosis. (a) Viability of wild-type, Bax ${ }^{-1-}, \mathrm{Bak}^{-1-}$ and Bax ${ }^{-1-} \mathrm{Bak}^{-1-}$ DKO cells. MEF cells stably overexpressing VAR F1L or vector, treated with $1.5 \mu \mathrm{M}$ thapsigargin and cultured for $24 \mathrm{~h}$. (b) Viability of $293 \mathrm{~T}$ cells transiently overexpressing either Bim $\mathrm{EL}_{\mathrm{L}}$ or Bid as well as F1L, Bcl-2 or vector control. Error bars are \pm S.E.M. with $n=3$

VAR F1L was able to neutralize only Bax-mediated apoptosis. Close examination of structures of VAR F1L complexes with Bid and Bak and VV F1L complexes with Bim and Bak did not reveal major differences in $\mathrm{BH} 3$ domain binding to the canonical binding groove (Supplementary Figure 4) that can explain the startlingly different ligand-binding behavior. The loss of Bim binding for VAR F1L is particularly noteworthy as VV-induced apoptosis is reduced in Bim-deficient cells, ${ }^{28}$ suggesting that Bim plays a substantial role during the cellular response to VV infection. Whether or not Bim is important for VAR infection has not been determined to date. In the case of Epstein-Barr virus BHRF1-mediated inhibition of apoptosis, $\mathrm{Bim}^{33}$ and $\mathrm{Bak}^{34}$ neutralization were shown to be critical, whereas in the case of myxoma virus M11L, ${ }^{20}$ Bax and Bak sequestration were identified as the primary mechanism of inhibition. However, in both cases, the mechanism of apoptosis inhibition was not defined in the context of a viral infection. Nonetheless, despite the inability to directly engage $\mathrm{Bim}$, and the very modest affinity to Bid, VAR F1L is able to counter both Bim- and Bid-mediated apoptosis.

In addition to raising intriguing questions about VAR biology, this striking insensitivity of VAR F1L to Bim raises questions about the regulation of $\mathrm{Bcl}-2$-mediated apoptosis. Direct activation of Bax and Bak via promiscuous or activator $\mathrm{BH} 3-$ only proteins has been shown to be an important route to trigger apoptosis, ${ }^{35-38}$ however, VAR F1L appears to be unlikely to act by $\mathrm{BH} 3-$ only protein sequestration to prevent Bax activation. Among the other alternatively proposed mechanisms invoked to control apoptosis, VAR F1L's ability to inhibit apoptosis is most readily explained by an indirect model based on sequestration of Bax and Bak, ${ }^{39,40}$ where Bax and Bak are held in an inactive configuration by a pro-survival $\mathrm{Bcl}-2$ family member. This is supported by our observations that VAR F1L is able to bind $\mathrm{BH} 3$ domain peptides from Bax and Bak, albeit at modest affinity, as well as the prevention of Bax- and Bak-induced growth arrest in yeast-based assays in the absence of any other cellular apoptosis regulatory proteins. Such a mechanism is also an integral part of the currently favored unified model, ${ }^{41}$ where a balance between direct activation and indirect activation ultimately yields control of intrinsic apoptosis. The insensitivity of VAR F1L to Bim, and indeed all tested BH3-only proteins, is striking in this context, and may make VAR F1L a useful tool molecule to further understand the interplay of the two main modes that underpin the unified model of apoptosis regulation.

Targeting of the apoptotic machinery is currently an intensely pursued strategy for the development of novel drugs for cancer therapy. ${ }^{42,43}$ Similarly, VAR F1L may be a valid target for development of antiviral therapeutics. Current strategies for the development of antiviral therapeutics against VAR have relied mostly on the use of homologous target molecules from VV, monkeypox or ectromelia virus, with only a small number of studies utilizing VAR-encoded proteins, ${ }^{44-46}$ and even fewer studies using their structures. ${ }^{47,48}$ The marked differences between VAR and VV F1L suggest that studies of VAR proteins may provide unexpected avenues for therapeutic intervention that may not be predicted based on available data from the closely related and much better understood VV. It also raises the question of how well current systems that mimic VAR model the behavior of this intriguing virus. VAR occupies a unique position as the sole human pathogen among the orthopoxviruses. As molecular determinants for this human-specific tropism remain essentially unknown, identification of a different mechanism of action and utilization of host factors used by a VAR virulence factor compared with its VV homolog suggest that studying VAR directly may be essential to understand its unique tropism.

\section{Materials and Methods}

All experiments were performed with WHO approval

Recombinant proteins and binding experiments: VAR_F1L $\Delta$ N38 $\Delta$ C 36 was amplified by PCR from expression-optimized F1L CDNA (Blue Heron), cloned into the pGEX-6P3 vector (Invitrogen, Melbourne, VIC, Australia) using BamHI and EcoRI, and expressed in E. coli BL21 DE3 pLysS cells. Cells were homogenized using an Avestin EmulsiFlex homogenizer in lysis buffer $(50 \mathrm{mM}$ Tris- $\mathrm{HCl}, \mathrm{pH} 8.0,150 \mathrm{mM}$ $\mathrm{NaCl}, 1 \mathrm{mM}$ EDTA). After centrifugation, the supernatant was applied to a glutathione sepharose column (GE Healthcare, Melbourne, VIC, Australia) and washed with lysis buffer. On-column cleavage was performed using Prescission Protease (GE Healthcare), and VAR F1L was eluted using lysis buffer. Subsequently, VAR F1L was subjected to gel-filtration chromatography in $25 \mathrm{mM}$ HEPES, pH 7.5, $150 \mathrm{mM}$ $\mathrm{NaCl}$ using a Superdex 200 column (GE Healthcare). Calorimetry data were collected on a VP-ITC (MicroCal) with VAR_F1L $\triangle$ N38 3 C 36 as previously described. ${ }^{23}$ Peptides used have been described previously. ${ }^{34}$

Crystallization and structure determination: VAR F1L:Bak or VAR F1L:Bid $\mathrm{BH} 3$ complexes were obtained by mixing VAR F1L with human Bak 26-mer or Bid 
34-mer peptide in a 1:1.25 molar ratio and concentrated using a centricon (Millipore) to $5 \mathrm{mg} / \mathrm{ml}$.

VAR F1L:Bak $\mathrm{BH} 3$ crystals were grown by the sitting drop method at room temperature in $1.7 \mathrm{M} \mathrm{MgSO}_{4}, 0.1 \mathrm{M}$ sodium acetate with $\mathrm{pH}$ 5.2.The crystals belong to space group 1121 with $a=124.774 \AA, b=68.762 \AA, c=171.598 \AA, \alpha=90^{\circ}$, $\beta=109.43^{\circ}, \gamma=90^{\circ}$. The asymmetric unit contains six VAR F1L chains and six Bak BH3 peptides, with $49 \%$ solvent content. Diffraction data were collected from crystals flash frozen in paratone at $100 \mathrm{~K}$ using beamline MX2 at the Australian Synchrotron (Melbourne, VIC, Australia).

VAR F1L:Bid BH3 crystals were grown by the sitting drop method at room temperature in $1.8 \mathrm{M}$ sodium acetate and $0.1 \mathrm{M}$ HEPES ( $\mathrm{pH}$ 6.5). The crystals belong to space group $\mid 121$ with $a=124.774 \AA, b=68.762 \AA, c=171.598 \AA, \alpha=90^{\circ}$, $\beta=109.43^{\circ}, \gamma=90^{\circ}$. The asymmetric unit contains one VAR F1L chain and one Bid BH3 peptides, with $49 \%$ solvent content. Diffraction data were collected from crystals flash frozen in paratone at $100 \mathrm{~K}$ using beamline MX2 at the Australian Synchrotron.

Diffraction data were processed with $\mathrm{XDS}^{49}$ and programs of the CCP4 suite. ${ }^{50}$ The VAR F1L:Bak BH3 and VAR F1L:Bid BH3 structures were solved by molecular replacement with PHASER $^{51}$ using F1L from the VV F1L structure as a search model (PDB 2VTY) and refined using Phenix.52 All data collection and refinement statistics are summarized in Supplementary Table 1. Figures were prepared using PyMol. ${ }^{53}$ Software was in some instances accessed via SBGrid. ${ }^{54}$

\section{Yeast colony assays}

Saccharomyces cerevisiae. W303 $\alpha$ cells were co-transformed with pGALL(TRP) vector only, pGALL(TRP)-Bcl-x , or pGALL(TRP)-VAR_F1L and pGALL(Leu)-Bak or pGALL(Leu)-Bax. pGALL(TRP) and pGALL(Leu) places genes under the control of a galactose inducible promoter. Cells were spotted as fivefold serial dilutions onto medium containing $2 \%(\mathrm{w} / \mathrm{v})$ galactose (inducing, 'ON'), which induces protein expression, or $2 \%(\mathrm{w} / \mathrm{v})$ glucose (repressing, 'OFF'), which prevents protein expression, as previously described. ${ }^{55}$ Plates were incubated for $48 \mathrm{~h}$ at $30{ }^{\circ} \mathrm{C}$ and then photographed.

Cell culture, transfection, lentiviral infection and cellular assays: Human embryonic kidney 293T (ATCC CRL-3216) and MEFs (a gift from D Huang) were cultured in Dubecco's modified Eagle's medium supplemented with $10 \%$ fetal calf serum (Sigma) at $37^{\circ} \mathrm{C}$ in a humidified $10 \% \mathrm{CO}_{2}$ incubator. Both bak ${ }^{-1-}$ and bax $^{-1-}$ MEFs were generated from E15 embryos in accordance with standard procedures and were infected with SV40 large T antigen-expressing lentiviruses as described. ${ }^{39,40}$

To generate lentiviral particles, human embryonic kidney 293T cells were transfected with packaging constructs pCMV $ð R 8.2$ and VSVg and the relevant lentiviral plasmid at a ratio of 1:0.4:0.6 using Fugene 6.0 transfection reagent (Roche Lifesciences, Indianapolis, IN, USA) following the manufacturer's instructions. The virus containing supernatants were harvested, filtered $(0.8 \mu \mathrm{m})$ and supplemented with polybrene $(4 \mathrm{mg} / \mathrm{ml})$. Target cells were infected with virus supernatant as described by Vince et al. ${ }^{56}$

MEF cells were seeded at $\sim 10000$ cells per well and allowed to adhere for $24 \mathrm{~h}$. The cells were then treated with Thapsigargin $(1.5 \mu \mathrm{M}$ final, Calbiochem, San Diego, CA, USA) or serum withdrawal for 24 and $48 \mathrm{~h}$. To monitor cell death, cells were stained with propidium iodide $(1.25 \mu \mathrm{g} / \mathrm{ml})$ and analyzed in a FACScan (Becton Dickinson). Values presented are the means \pm S.D. $(n=3)$. Differences were considered significant at $P<0.05$.

293T cells were seeded @ 150000 cells per well in six-well plates in complete Dubecco's modified Eagle's medium and incubated $\mathrm{O} / \mathrm{N} @ 37^{\circ} \mathrm{C}, 5 \% \mathrm{CO}_{2}$. Next day, the cells were transfected with $0.25 \mu \mathrm{g} \mathrm{Bim,} \mathrm{Bid} \mathrm{or} \mathrm{Bcl2} \mathrm{and} 0.5 \mu \mathrm{g} \mathrm{F1L}$ or control plasmid DNA per well using Xtreme Gene 9 transfection reagent (Roche Lifesciences; Catalog number 06365787001). $24 \mathrm{~h}$ post transfection, cells were harvested by trypsinization and PI uptake measured by flow cytometry. Error bars presented are the standard error of the means $(n=3)$.

\section{Conflict of Interest}

The authors declare no conflict of interest.

Acknowledgements. We thank A Wardak for technical assistance; staff at the Australian Synchrotron for assistance with diffraction data collection; CSIRO C3 Centre for assistance with crystallization. This work was supported by the National Health and Medical Research Council Australia (Project Grant APP1007918 and
Fellowship 637372 to MK, Fellowship and Program Grant to PMC), Australian Research Council (Fellowship FT130101349 to MK), the Cooperative Research Center for Biomarker Translation (scholarship to BM), the Victorian State Government Operational Infrastructure Support and the Australian Government NHMRC IRIISS. Data deposition: Coordinates for F1L were deposited with the Protein Data Bank, accession code 5ajj and 5ajk.

1. Kaiser J. Smallpox vaccine. A tame virus runs amok. Science 2007; 316: 1418-1419.

2. Poland GA, Grabenstein JD, Neff JM. The US smallpox vaccination program: a review of a large modern era smallpox vaccination implementation program. Vaccine 2005; 23: 2078-2081.

3. Jacobs BL, Langland JO, Kibler KV, Denzler KL, White SD, Holechek SA et al. Vaccinia virus vaccines: past, present and future. Antiviral Res 2009; 84: 1-13.

4. Bray M. Pathogenesis and potential antiviral therapy of complications of smallpox vaccination. Antiviral Res 2003; 58: 101-114.

5. Stittelaar KJ, Neyts J, Naesens L, van Amerongen G, van Lavieren RF, Holy A et al. Antiviral treatment is more effective than smallpox vaccination upon lethal monkeypox virus infection. Nature 2006; 439: 745-748.

6. Baker R, Bray M, Huggins JW. Potential antiviral therapeutics for smallpox, monkeypox and other orthopoxvirus infections. Antiviral Res 2003; 57: 13-23.

7. Yang G, Pevear DC, Davies MH, Collett MS, Bailey T, Rippen S et al. An orally bioavailable antipoxvirus compound (ST-246) inhibits extracellular virus formation and protects mice from lethal orthopoxvirus challenge. J Virol 2005; 79: 13139-13149.

8. Reeves PM, Bommarius B, Lebeis S, McNulty S, Christensen J, Swimm A et al. Disabling poxvirus pathogenesis by inhibition of Abl-family tyrosine kinases. Nat Med 2005; 11: 731-739.

9. Yang HL, Kim SK, Kim M, Reche PA, Morehead TJ, Damon IK et al. Antiviral chemotherapy facilitates control of poxvirus infections through inhibition of cellular signal transduction. J Clin Invest 2005; 115: 379-387.

10. Fauci AS, Challberg MD. Host-based antipoxvirus therapeutic strategies: turning the tables. $J$ Clin Invest 2005; 115: 231-233.

11. Sliva K, Schnierle B. From actually toxic to highly specific - novel drugs against poxviruses. Virol J 2007; 4: 8

12. Graham KA, Opgenorth A, Upton C, McFadden G. Myxoma virus M11L ORF encodes a protein for which cell surface localization is critical in manifestation of viral virulence. Virology 1992; 191: 112-124.

13. Banadyga L, Lam SC, Okamoto T, Kvansakul M, Huang DC, Barry M. Deerpox virus encodes an inhibitor of apoptosis that regulates Bak and Bax. J Virol 2011; 85: 1922-1934.

14. Banadyga L, Veugelers K, Campbell S, Barry M. The fowlpox virus BCL-2 homologue, FPV039, interacts with activated Bax and a discrete subset of $\mathrm{BH} 3$-only proteins to inhibit apoptosis. J Virol 2009; 83: 7085-7098.

15. Wasilenko ST, Stewart TL, Meyers AF, Barry M. Vaccinia virus encodes a previously uncharacterized mitochondrial-associated inhibitor of apoptosis. Proc Natl Acad Sci USA 2003; 100: 14345-14350.

16. Okamoto T, Campbell S, Mehta N, Thibault J, Colman PM, Barry M et al. Sheeppox virus SPPV14 encodes a Bcl-2-like cell death inhibitor that counters a distinct set of mammalian proapoptotic proteins. J Virol 2012; 86: 11501-11511.

17. Youle RJ, Strasser A. The BCL-2 protein family: opposing activities that mediate cell death. Nat Rev Mol Cell Biol 2008; 9: 47-59.

18. Kvansakul M, Hinds MG. Structural biology of the Bcl-2 family and its mimicry by viral proteins. Cell Death Dis 2013; 4: e909.

19. Bartlett N, Symons JA, Tscharke DC, Smith GL. The vaccinia virus N1L protein is an intracellular homodimer that promotes virulence. J Gen Virol 2002; 83: 1965-1976.

20. Kvansakul M, van Delft MF, Lee EF, Gulbis JM, Fairlie WD, Huang DC et al. A structural viral mimic of prosurvival bcl-2: a pivotal role for sequestering proapoptotic bax and bak. Mol Cell 2007; 25: 933-942

21. Douglas AE, Corbett KD, Berger JM, McFadden G, Handel TM. Structure of M11L: A myxoma virus structural homolog of the apoptosis inhibitor, Bcl-2. Protein Sci 2007; 16: 695-703.

22. Campbell S, Thibault J, Mehta N, Colman PM, Barry M, Kvansakul M. Structural insight into BH3 domain binding of vaccinia virus antiapoptotic F1L. J Virol 2014; 88: 8667-8677.

23. Kvansakul M, Yang H, Fairlie WD, Czabotar PE, Fischer SF, Perugini MA et al. Vaccinia virus anti-apoptotic $\mathrm{F} 1 \mathrm{~L}$ is a novel $\mathrm{Bcl}-2$-like domain-swapped dimer that binds a highly selective subset of BH3-containing death ligands. Cell Death Differ 2008; 15: 1564-1571.

24. Aoyagi M, Zhai D, Jin C, Aleshin AE, Stec B, Reed JC et al. Vaccinia virus N1L protein resembles a B cell lymphoma-2 (Bcl-2) family protein. Protein Sci 2007; 16: 118-124.

25. Cooray S, Bahar MW, Abrescia NG, McVey CE, Bartlett NW, Chen RA et al. Functional and structural studies of the vaccinia virus virulence factor N1 reveal a Bcl-2-like anti-apoptotic protein. J Gen Virol 2007; 88: 1656-1666.

26. Campbell S, Hazes B, Kvansakul M, Colman P, Barry M. Vaccinia virus F1L interacts with Bak using highly divergent $\mathrm{Bcl}-2$ homology domains and replaces the function of $\mathrm{Mcl}-1$. J Biol Chem 2010; 285: 4695-4708.

27. Fischer SF, Ludwig H, Holzapfel J, Kvansakul M, Chen L, Huang DCS et al. Modified vaccinia virus ankara protein $\mathrm{F} 1 \mathrm{~L}$ is a novel $\mathrm{BH} 3$-domain binding protein and acts together 
with the early viral protein E3L to block virus-associated apoptosis. Cell Death Differ 2006; 13: $109-118$.

28. Taylor JM, Quilty D, Banadyga L, Barry M. The vaccinia virus protein F1L interacts with Bim and inhibits activation of the pro-apoptotic protein Bax. J Biol Chem 2006; 281 : 39728-39739.

29. Altmann M, Hammerschmidt W. Epstein-Barr virus provides a new paradigm: a requirement for the immediate inhibition of apoptosis. PLOS Biol 2005; 3: e404.

30. Dobbelstein M, Shenk T. Protection against apoptosis by the vaccinia virus SPI-2 (B13R) gene product. J Virol 1996; 70: 6479-6485.

31. Kvansakul M, Hinds MG. The structural biology of BH3-only proteins. Meth Enzym 2014; 544: 49-74.

32. Rautureau GJ, Yabal M, Yang H, Huang DC, Kvansakul M, Hinds MG. The restricted binding repertoire of $\mathrm{Bcl}-\mathrm{B}$ leaves Bim as the universal $\mathrm{BH}$-only prosurvival $\mathrm{Bcl}-2$ protein antagonist. Cell Death Dis 2012; 3: e443.

33. Desbien AL, Kappler JW, Marrack P. The Epstein-Barr virus Bcl-2 homolog, BHRF1, blocks apoptosis by binding to a limited amount of Bim. Proc Natl Acad Sci USA 2009; 106: 5663-5668.

34. Kvansakul M, Wei AH, Fletcher JI, Willis SN, Chen L, Roberts AW et al. Structural basis for apoptosis inhibition by Epstein-Barr virus BHRF1. PLoS Pathog 2010; 6: e1001236.

35. Czabotar PE, Westphal D, Dewson G, Ma S, Hockings C, Fairlie WD et al. Bax crystal structures reveal how $\mathrm{BH} 3$ domains activate bax and nucleate its oligomerization to induce apoptosis. Cell 2013; 152: 519-531.

36. Du H, Wolf J, Schafer B, Moldoveanu T, Chipuk JE, Kuwana T. BH3 domains other than Bim and Bid can directly activate Bax/Bak. J Biol Chem 2011; 286: 491-501.

37. Gavathiotis E, Reyna DE, Davis ML, Bird GH, Walensky LD. BH3-triggered structural reorganization drives the activation of proapoptotic BAX. Mol Cell 2010; 40: 481-492.

38. Chi X, Kale J, Leber B, Andrews DW. Regulating cell death at, on, and in membranes. Biochim Biophys Acta 2014; 1843: 2100-2113.

39. Willis SN, Chen L, Dewson G, Wei A, Naik E, Fletcher Jl et al. Pro-apoptotic Bak is sequestered by Mc1-1 and Bcl-xL, but not Bcl-2, until displaced by BH3-only proteins. Genes Devel 2005; 19: 1294-1305.

40. Willis SN, Fletcher Jl, Kaufmann T, van Delft MF, Chen L, Czabotar PE et al. Apoptosis initiated when BH3 ligands engage multiple Bcl-2 homologs, not Bax or Bak. Science 2007; 315: $856-859$

41. Llambi F, Moldoveanu T, Tait SW, Bouchier-Hayes L, Temirov J, McCormick LL et al. A unified model of mammalian BCL-2 protein family interactions at the mitochondria. Mol Cell 2011; 44: 517-531.

42. Lessene G, Czabotar PE, Colman PM. BCL-2 family antagonists for cancer therapy. Nat Rev Drug Discov 2008; 7: 989-1000.

43. Kvansakul M, Hinds MG. The Bcl-2 family: structures, interactions and targets for drug discovery. Apoptosis 2015; 20: 136-150.
44. Aleshin AE, Drag M, Gombosuren N, Wei G, Mikolajczyk J, Satterthwait AC et al. Activity, specificity, and probe design for the smallpox virus protease K7L. J Biol Chem 2012; 287: 39470-39479.

45. Gileva IP, Nepomnyashchikh TS, Ryazankin IA, Shchelkunov SN. Recombinant TNF-binding protein from variola virus as a novel potential TNF antagonist. Biochem Biokhimiia 2009; 74: 1356-1362.

46. Mohamed MR, Rahman MM, Lanchbury JS, Shattuck D, Neff C, Dufford M et al. Proteomic screening of variola virus reveals a unique NF-kappaB inhibitor that is highly conserved among pathogenic orthopoxviruses. Proc Natl Acad Sci USA 2009; 106: 9045-9050.

47. Perry K, Hwang Y, Bushman FD, Van Duyne GD. Structural basis for specificity in the poxvirus topoisomerase. Mol Cell 2006; 23: 343-354.

48. Phan J, Tropea JE, Waugh DS. Structure-assisted discovery of Variola major H1 phosphatase inhibitors. Acta Cryst D 2007; 63: 698-704.

49. Kabsch W. Xds. Acta Cryst D 2010; 66: 125-132.

50. Winn MD, Ballard CC, Cowtan KD, Dodson EJ, Emsley P, Evans PR et al. Overview of the CCP4 suite and current developments. Acta Cryst D 2011; 67: 235-242.

51. Storoni LC, McCoy AJ, Read RJ. Likelihood-enhanced fast rotation functions. Acta Cryst $D$ 2004; 60: 432-438.

52. Adams PD, Afonine PV, Bunkoczi G, Chen VB, Davis IW, Echols N et al. PHENIX: a comprehensive Python-based system for macromolecular structure solution. Acta Cryst $D$ 2010; 66: 213-221.

53. DeLano WL The PyMOL molecular graphics system, 2002. www.pymol.org.

54. Morin A, Eisenbraun B, Key J, Sanschagrin PC, Timony MA, Ottaviano M et al. Collaboration gets the most out of software. elife 2013; 2: e01456.

55. Jabbour AM, Puryer MA, Yu JY, Lithgow T, Riffkin CD, Ashley DM et al. Human Bcl-2 cannot directly inhibit the Caenorhabditis elegans Apaf-1 homologue CED-4, but can interact with EGL-1. J Cell Sci 2006; 119: 2572-2582.

56. Vince JE, Wong W, Khan N, Feltham R, Chau D, Ahmed AU et al. IAP antagonists target clAP1 to induce TNF $\alpha$-dependent apoptosis. Cell 2007; 131: 682-693.

(i) Cell Death and Disease is an open-access journal published by Nature Publishing Group. This work is licensed under a Creative Commons Attribution 4.0 International License. The images or other third party material in this article are included in the article's Creative Commons license, unless indicated otherwise in the credit line; if the material is not included under the Creative Commons license, users will need to obtain permission from the license holder to reproduce the material. To view a copy of this license, visit http://creativecommons.org/licenses/by/4.0/

Supplementary Information accompanies this paper on Cell Death and Disease website (http://www.nature.com/cddis) 